\title{
PERFORMANCE MANAGEMENT OF AN INTEGRATED WIND TURBINE-FUEL CELL/MICRO TURBINE HYBRID SYSTEM
}

\author{
Ahmed M. Azmy \\ Department of Electrical Power and Machines Engineering, Faculty of Engineering, \\ Tanta University, Tanta, Egypt
}

\begin{abstract}
This paper concerns with the management of the dynamic performance of a wind turbine integrated with a fuel cell/micro turbine hybrid system for continuous power supply. The objective is to mitigate some problems associated with the intermittent nature of wind energy and to ensure a continuous power supply to the load. The strategy is based on maximizing the power extracted from the wind, where the excess of power is utilized to generate hydrogen through a water electrolyser. This hydrogen is then used for supplying the fuel cell, which drives a downstream micro-turbine. The fuel-cell/micro-turbine hybrid unit is used to provide the deficit power when the wind power is not enough to meet the load demand. At the same time, it is used to smooth the oscillatory performance of the wind power. This configuration gives more flexibility since the generated power from the fuel cell and micro turbine can be controlled individually. Detailed models for the wind power source and the hybrid fuel cell/micro turbine system are presented. Extensive simulation results are introduced to ascertain the feasibility and reliability of the proposed management approach.

يهتم هذا البحث بتظيم الأداء الديناميكي لوحدة توليد مركبة تضم تربينة هواثية مرتبطة بوحدة خلايا وقود مع تربينة غازية

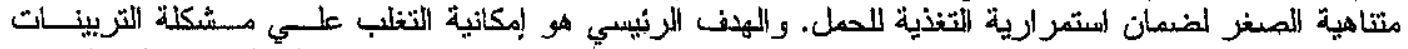

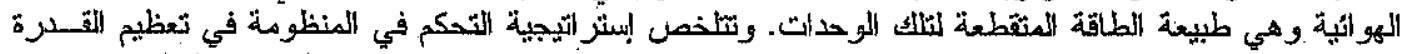

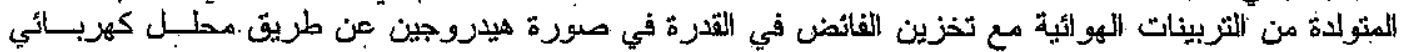

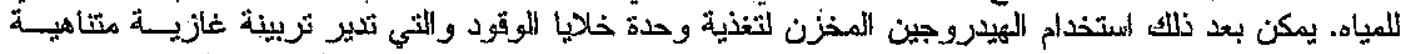

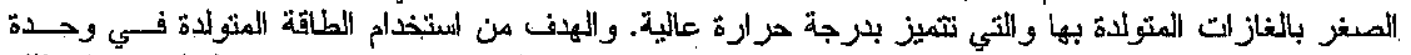

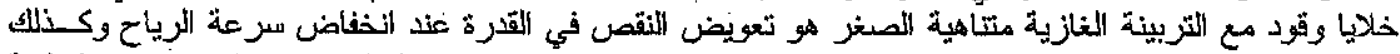

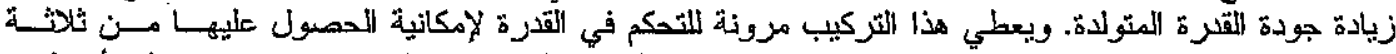

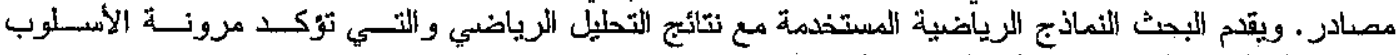

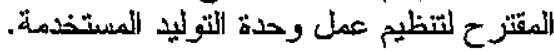

Keywords: Fuel cell, management system, micro turbine, renewable energy, wind turbine

\section{INTRODUCTION}

Variable-speed wind turbines represent environmentfriendly types of Distributed Generation (DG) [1]. Wind-turbines" WTs" are well developed and are being widely used in electric power systems [2]. Therefore, the penetration level and contribution of such sources in power systems are growing to support the existing power networks. With this increase, the intermittent nature of wind will be reflected to the power system and the supplied power will fluctuate with wind turbulences [2]. The adjacent loads will be most affected by this irregular nature and thus, WTs cannot be located near major load centres. These problems characterize the main barrier of utilizing wind power in large scale.

An obvious solution is using a hybrid configurations by integrating the WT with other reliable sources [2]. For prolonged periods, the wind-diesel combination is utilized to provide a relatively smooth generation
[3] and [4]. However, diesel units contribute in the problems associated with the fossil fuel and greenhouse gasses [3] and [4]. Alternatively, fuel cells "FCs" are proposed to benefit the flexibility of the stored electrochemical energy to overcome the mentioned problems [5] -[7]. The attempts in this direction, however, did not overcome all problems concerning this subject. The simple modelling of the FC introduced in [1], for instance, did not provide the exact response of FCs in the hybrid configuration due to the linearity of the assumed model. The models introduced in [2] and [8] describe the thermodynamic nature of FCs but the exact electrical modelling necessitates involving the time constant of the current and the time delay of the chemical process. Therefore, the FC seems to follow the wind variations instantaneously. Also, the power transfer analysis given in [6] assumed the $\mathrm{FC}$ as an ideal source, which is not appropriate for dynamic analysis of such systems. 
When FCs utilize hydrogen as a fuel, they respond fairly fast to load variations. However, they may not be able to respond to fast variations in load demand especially for large-capacity units [9]. The Fuel Cell/Micro Turbine Hybrid System (FCMT) is a promising unit that can provide very high efficiency, compact design, fuel flexibility, acceptable capital cost, superior environmental performance, and possibility of independent operation of the two units [10].

This paper suggests the use of a new configuration by operating the WT with a FCMT unit. According to this configuration, the electric power can be obtained from three sources, i.e. the wind generator, the FC stack and the Micro-Turbine (MT) generator. In addition, thermal power can be obtained from the MT, which offers another advantage for the proposed system. However, the utilization of the thermal power and the corresponding thermal management system, which are discussed in previous works [10] and [11] are out of the scope of this paper. The fast load variations can be better compensated through the simultaneous regulation of generated power from the $\mathrm{FC}$ and the MT.

\section{SYSTEM DESCRIPTION}

Fig. 1 illustrates a schematic diagram of the proposed system. As shown in the figure, the WT is operating in parallel with the FCMT, where the electric power is obtained from three sources. The management system regulates the output power from the $\mathrm{FC}$ and the MT according to the generated power from the WT and the load demand to satisfy the load requirements.

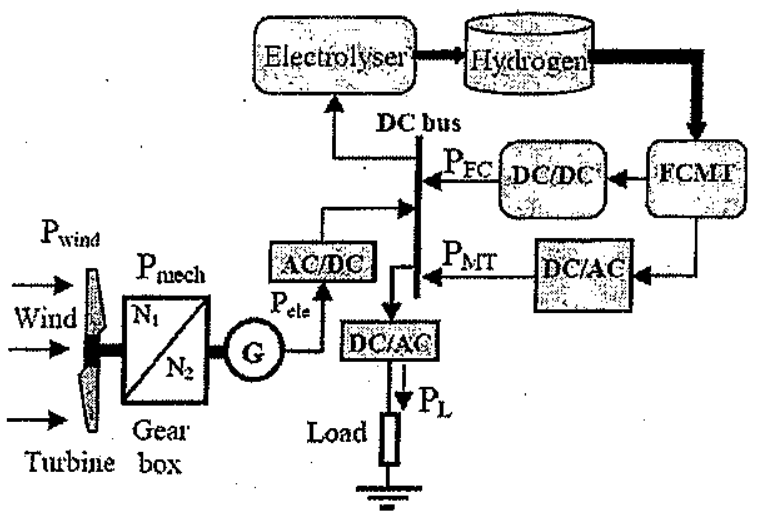

Fig. 1, A schematic diagram of the proposed system

For this configuration, it is possible to extract the maximum possible power from the wind. The power from the FCMT is used to compensate for the insufficiency to cover the load requirements. When the wind power exceeds the load requirements, the excess of power is converted to hydrogen through the water electrolyser to represent the source of the FCMT unit. The strategy depends also on regulating the output power from the FCMT unit to smooth out the oscillatory performance of the wind power.

\section{WIND ENERGY}

The relations describing the operation of the WT are given for the mechanical torque and the tip-speed ratio " $\lambda$ ", as follows [11][12] and [13]:

$$
\begin{aligned}
& T_{m}=\frac{1}{2} \rho \cdot \eta_{g b} \cdot A_{s} \cdot C_{p} \cdot R \frac{V_{W}^{2}}{\lambda} \\
& \lambda=\frac{\text { speed of tip }}{\text { wind speed }}=\frac{R \Omega}{V_{W}}
\end{aligned}
$$

Where:

$A_{s}$ is the swept area

$C_{p}$ is the power coefficient

$\mathrm{R}$ is the rotor radius of the WT

$V_{W}$ is the wind speed

$\eta_{\mathrm{gb}}$ is the efficiency of the mechanical gearing

$\rho$ is the air density $\left(\mathrm{kg} / \mathrm{m}^{3}\right)$

$\Omega$ is the angular speed of the WT

The relation between tip speed ratio and power coefficient for different blade pitch angles $(\beta)$ can be derived and used in the previous equations. The WT drives a doubly-fed induction generator "DFIG", which is the most commonly used for wind power generation [13]. In this configuration, the rotor terminals are fed with a symmetrical three-phase voltage with variable amplitude and frequency. Through the variation of the rotor voltage, the rotor speed can be adjusted according to the control strategy to allow for the optimum operating point at any wind speed. The detailed model of the DFIG is found in [13].

\section{MODELLING OF THE HYBRID FCMT UNIT}

The FCMT unit comprises a high-temperature $\mathrm{FC}$, an air compressor, a bigh speed gas turbine, and a Permanent Magnet Synchronous Generator "PMSG" [14]. Normally, a solid oxide FC is used since it offers temperatures up to $1000^{\circ} \mathrm{C}$. The exhaust gases in the $\mathrm{FC}$ contains enough energy to drive the downstream turbine replacing the classical combustor [14] and [15]. Using this configuration, electric power is extracted from the stack and the PMSG at the same time with input fuel to the $\mathrm{FC}$ alone from the stored hydrogen. In some cases the combustor is used in the running mode to increase the generated power. Fig. 2 illustrates the FCMT configuration. The task of the heat exchanger is to increase the temperature of the pressurized air before entering the FC and hence, increase the unit efficiency. The detailed modelling of the heat exchanger is given in a previous work [10].

The air is compressed and then forced to pass through the heat exchanger before entering the $\mathrm{FC}$. The hydrogen is electrochemically processed in the 
stack to produce water, heat, and DC power. A downstream turbine is used to extract more power by expanding the exhaust gas from the FC as a working fluid. This mode of operation is called the "topping mode" regarding the position of the $\mathrm{FC}$ with respect to the MT.

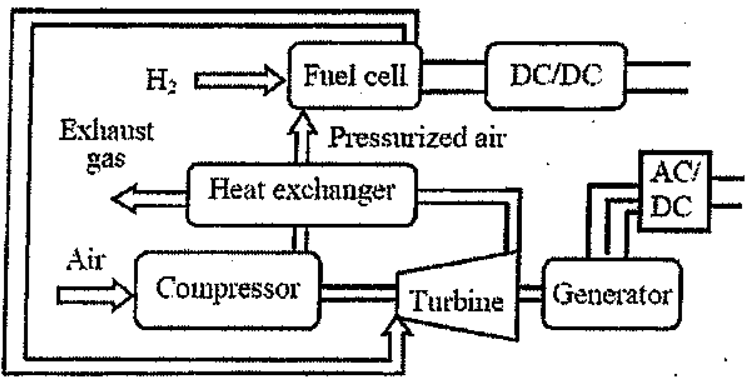

Fig. 2, A schenatic diagram of the hybrid FCMT unit

The $\mathrm{FC}$ is working independently on the $\mathrm{MT}$ since it has its own fuel source and controllers. On the other hand, the operation of the MT depends on the thermal power of the $\mathrm{FC}$, which is proportional to the FC electrical power. To model the dynamic interdependency of the $\mathrm{MT}$ and $\mathrm{FC}$, the $\mathrm{FC}$ electrical power and its thermal power, are calculated. The management system regulates the thermal power entering the turbine and thus regulates the MT electric power. The dynamic interdependency of the FCMT is shown in Fig. 3.

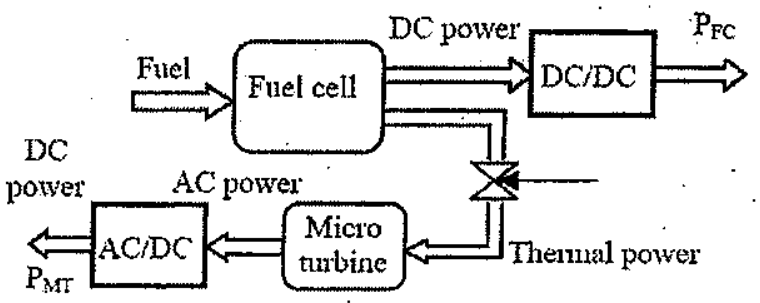

Fig. 3, Dynamic interdependency of the hybrid FCMT unit

The terminal voltage of the $\mathrm{FC}$ is controlled by regulating the firing angles of the $\mathrm{DC} / \mathrm{DC}$ converter. In addition, the generated power from the MT is converted to the $\mathrm{DC}$ form, where the terminal voltage is controlled. The electric power of the FC can be regulated, if required; by adjusting the input fuel rate. It is required to regulate the thermal power to the MT to control its generated electric power.

\subsection{Electrolyser modelling}

The water electrolyser is used to store the surplus power from wind in the form of Hydrogen by the decomposition of liquid water $\left[\mathrm{H}_{2} \mathrm{O}\right]$ into hydrogen gas $\left[\mathrm{H}_{2}\right]$ and oxygen gas $\left[\mathrm{O}_{2}\right]$. This is accomplished by passing electrical current between two electrodes separated by an aqueous electrolyte [16] and [17].
The previous process takes the following form [17].

$\mathrm{H}_{2} \mathrm{O}+$ electrical energy $\rightarrow \mathrm{H}_{2}+1 / 2 \mathrm{O}_{2}$

The production rate of hydrogen through the electrolyser " $\mathrm{V}_{\mathrm{h} 2}$ " depends on the transfer rate of electrons at the electrodes and thus on the circuit current [2], [16] and [17].

$\mathrm{V}_{\mathrm{h} 2}=\eta_{\mathrm{F}} \mathrm{n}_{\mathrm{c}} \mathrm{i}_{\mathrm{e}} / 2 / \mathrm{F}(\mathrm{mol} / \mathrm{s})$

Where: $\eta_{F}$ is the Faraday's efficiency, $\boldsymbol{n}_{\mathrm{c}}$ is the number of series electrolyser cells, $i_{c}$ is the electrolyser current, and F is Faraday's constant. The Faraday efficiency refers to the ratio between the actual and theoretical maximum amount of the produced hydrogen. For simplicity, the faraday efficiency is assumed to be constant and hence, the production rate of hydrogen is proportional to the electrolyser current [2], [16].

$\mathrm{V}_{\mathrm{h} 2}=5.18 \mathrm{e}^{-6} \cdot \mathrm{i}_{\mathrm{e}} \quad($ moles $/ \mathrm{s})$

\subsection{Fuel cell modelling}

The block-diagram model describing the dynamics of the FC is illustrated in Fig. 4 [11]. The chemical process inside the stack of the FC requires a delay time, which is modelled as a first-order time delay. The time delay " $T_{s}$ " depends on the size and type of the FC itself [11]. The simulation of the steady-state characteristic including the thermodynamic relations is accomplished by introducing a non-linear resistance to represent all kinds of voltage drops in the stack. The characteristic of any FC is given by a curve between the supplied current and the terminal voltage. Thus, it is possible for a certain curve to calculate the voltage drop and derive the corresponding non-linear loss resistance of the unit.

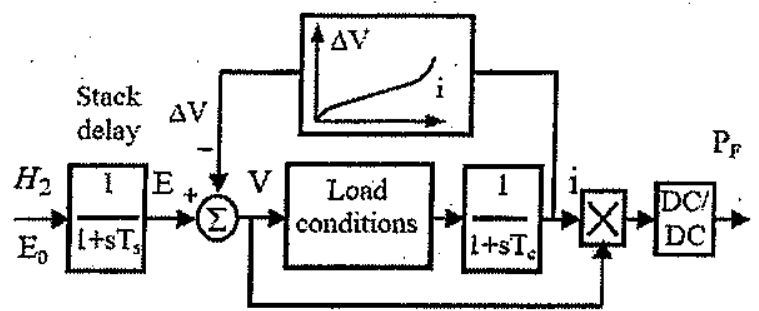

Fig. 4, Modelling of the fuel cell

The resistance, which represent the voltage-current characteristics, can be obtained from real measurements or using the Nernest and ButlerVolmer equations [18]. In addition, an inductor is introduced to take into account the time constant associated with the current. A DC/DC power conditioner is used to convert the DC stack power to $\mathrm{AC}$ form. The symbols are as follows:

$\mathrm{E}_{0}$ is the open circuit reversible cell potential (representing the input fuel rate), "p.u."

$\mathrm{E}$ is the same voltage delayed with a time $\mathrm{T}_{\mathrm{s}}$ "p.u." $\mathrm{V}$ is the DC output voltage from the stack, "p.u." 
$T_{s}$ is the stack time delay, " $\mathrm{s}$ "

$\mathrm{T}_{\mathrm{c}}$ is the time constant related to the current, " $\mathrm{s}$ ". $\Delta V$ is the total voltage drop in the stack, "p.u." $P_{\mathrm{FC}}$ is the output power from the fuel cell, "p.u."

The operation of FCs necessitates maintaining the stack temperature constant under all operating conditions depending on a heat management system, whose details are given in a previous work [10]. The ratio of produced electrical and thermal power is assumed to be constant. Hence, the increase of the input fuel to the unit will increase the generated electric and thermal power.

\subsection{Micro-Turbine Modelling}

MTs are characterized by small and compact construction and high-speed operation [19]. It consists of a compressor, a combustor, and a turbine [19]. However, the hybrid configuration eliminates the combustor, with a PMSG is used to convert the mechanical energy of the turbine to electrical energy. Regardless of the high speed of the PMSG, the conversion of the generated power to the $D C$ form gives the possibility to obtain the suitable frequency in the second conversion process. For simplicity, the PMSG is represented in this study by a simple first order model.

Fig. 5 shows the block diagram of the MT dynamic model [20]. The combustor is eliminated and a signal representing the power contained in the FC exhaust " $\mathrm{P}_{\mathrm{fc}}$ " is added to the output signal from the speed governor. The output from the governor represents the rejected exhaust defined by the management system as will be explained. The summation of the two signals, which represents the net useful thermal power, is used as the turbine input. The offset $\left(\mathrm{W}_{\min }\right)$ in the figure represents the fuel demand at no-load condition. The turbine is simulated using the wellknown function " $f$ " as follows:

$f=1.3\left(W_{\mathbf{f}}-W_{\min }\right)+0.5(1-\omega)$
The main symbols in the figure are as follows:

$\mathrm{W}_{\min }$ offset representing the fuel demand at no-load

$\mathrm{H}$ inertia constant

$\mathrm{K}_{\mathrm{g}}, \mathrm{K}_{\mathrm{gen}}$ gains of speed governor and generator

$V_{\text {ref, }}, f_{\text {ref }}, \omega_{\text {ref }}$ reference voltage, frequency, and angular speed respectively

$P_{f c}, P_{\text {elee }}, P_{m}$ power from exhaust air, inputelectrical, and mechanical power, respectively

$\tau_{\mathrm{g}}, \tau_{\mathrm{vp}}, \tau_{\text {gen }}$ lag-time constants of speed governor, valve positioner, and generator respectively

\section{MANAGEMENT SYSTEM}

The control strategy is to maximize the wind power. The power generated from the FCMT unit is used to balance the offset between the source and the load consumption. In addition, it can be used to smooth out the fluctuations caused by wind-speed variations. The system can be considered to operate in three modes.

- In the first mode, the power from the WT exceeds the load demand and a maximum power tracking technique is followed. In this case, the excess of power is stored in the form of hydrogen through the electrolyser. The FCMT unit can be completely switched off since there is no need for its power. However, it can be used depending on the operator if the hydrogen storage tank is full or to smooth out the fluctuations caused by wind-speed variations. In addition, it can be used to provide thermal power if the priority is directed to the thermal load demand.

- In the second mode, the wind power is not enough to supply the load demand. It is necessary in this mode to operate the FCMT unit to contribute in supplying the load by providing the deficit power. The stored hydrogen.is used as a fuel to supply the stack of the FCMT unit, while the WT operates in the maximum power tracking mode

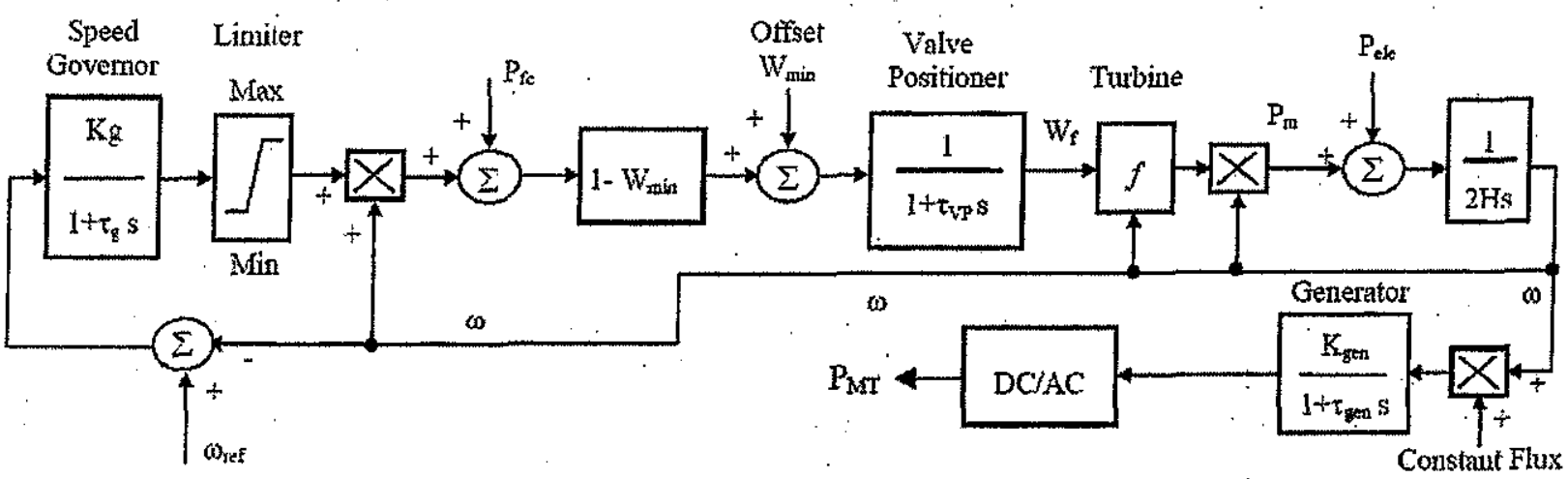

Fig. 5, Model of the micro-turbine generating unit including an input signal representing the power from the fuel cell exhaust 
- The last mode is the complete shutdown of the WT below cut-in or above cut-off wind speeds. The FCMT unit is used alone to supply the load with a special interest to the amount of the stored hydrogen to ensure continuous load supply. It is possible in this mode to use a load dispatch technique to save power for most important loads.

In each mode, a different control strategy is followed. The WT is operated in a variable speed mode, where the blade-pitch angle controller attempts to trace back the maximum power point. Above the rated wind speed, the WT is regulated for a constant rotor speed operation.

\subsection{Maximum Power Point Tracking}

With the variation of the tip-speed ratio, the power coefficient varies with a maximum value at a corresponding value for the tip-speed ratio. This results in the operation of the turbine at its maximum efficiency. The variation of the rotor speed to achieve this target is accomplished through the variation of the blade pitch angle and by the variation of the rotor voltage [13]. With the variation of the wind speed, the rotor speed has to be modified according to the maximum power line. The wind speed can be given in terms of the optimum rotor speed and tip-speed ration as follows [8].

$$
\begin{aligned}
& V_{W}=\frac{R \Omega_{o p t}}{\lambda_{o p t}} \\
& T_{m-t \text { arget }}=\frac{1}{2} \rho \cdot \eta_{g b} \cdot A_{s} \cdot C_{p} \cdot R^{3} \frac{\Omega_{o p t}^{2}}{\lambda_{o p t}^{3}}=k_{o p t} \Omega_{o p t}^{2} \\
& P_{m}=\frac{1}{2} \rho \cdot \eta_{g b} \cdot A_{s} \cdot C_{p}\left(\frac{R \Omega_{o p t}}{\lambda_{o p t}}\right)^{3}
\end{aligned}
$$

The optimal tip-speed ratio and power coefficient for each wind speed are calculated and the corresponding rotor speed is obtained. The rotor speed is taken as a reference to define the setting point of the controllers. This signal is compared with the turbine actual rotorspeed, where the error signal drives two PI controllers. The PI controllers adjust the blade pitch angle and the rotor voltage to reach the optimum rotor speed.

\subsection{Management of the FCMT Unit}

The management of the FCMT unit depends mainly on the wind power and load demand. The strategy can be summarized in the following three modes:

- If no power is generated in the WT, the FCMT unit operates alone with its separate controllers. The control action is to regulate the amount of hydrogen according to the load demand. In the steady state, the MT utilizes the full thermal power extracted from the FC stack. In addition, the voltage and frequency are controlled during the DC/AC conversion. The management system in this mode operates in two states.

i.If the stored hydrogen exceeds or equals $40 \%$ of tank capacity, the FCMT supplies the full load.

ii.If the stored hydrogen is less than $40 \%$ of the tank capacity, a load dispatch strategy is applied to prolong supplying period of significant loads.

- If the WT generates power that is less than the load requirements, the FCMT unit operates to provide the deficit power. To meet the load demand, two control actions are applied. The first is the regulation of the amount of hydrogen depending on the deficit power. This deficit represents the error signal to a PI controller, which defines the hydrogen flow rate. The second is the regulation of the thermal power extracted from the FC stack rather than using the full thermal power in the MT. Similar to the previous state, the voltage and frequency are controlled during the DC/AC conversion.

- If the wind power exceeds the load demand, the FCMT can operate to smooth out the generated power especially when the hydrogen tank is full. The FCMT operation is required if the fluctuations due to wind-speed variations are high and/or when the thermal power generated in the FCMT is necessary. Thus, the management systern operates in two states:

i. If the turbine operates alone, it is controlled to operate at its maximum power.

ii. If the FCMT unit operates in parallel with the WT, the strategy is similar to the second mode. Unlike previous cases, PID controllers are used in this mode.

\subsection{Power converter modules}

The three power sources are interfaced with the DC bus through power electronic devices. A DC/DC converter is used with the FC and two rectifiers are use with the two AC generators driven by the WT and the $\mathrm{MT}$. In the case of malfunctioning of any source, a diode connected at the output of each source will disconnect this source from the system. The DC bus voltage is kept constant by regulating the output voltage of these three devices using PI controllers. On the other hand, the load is supplied from the DC bus through a $\mathrm{DC} / \mathrm{AC}$ inverter with voltage and frequency controllers.

The objectives of the controllers are to maintain a fixed load voltage and frequency. The output $D C$ voltage from the $\mathrm{FC}$ is converted to a fixed value using a boost converter regulated by a PI controller [ 8 and 16]. The PI controller changes the duty ratio of the boost converter depending on the comparison between the feedback signal from the output DC voltage and the setting value. Controlled rectifiers are used with the PMSG and the DFIG to convert the output voltage 
to regulated DC form [8]. The firing angles are adjusted using PI controllers to ensure fixed DC voltage. A pulse width modulation technique is used to obtain the furing angles of the inverter that converts the DC bus voltage to an AC form to supply the load. A PI controller is used to adjust the modulation index to maintain the $\mathrm{AC}$ load voltage at the desired value. The controllers associated with the grid side and the rotor side converters of the DFIG are similar to those introduced in [12].

\section{SIMULATION RESULTS}

To examine the system, some disturbances are simulated. The first mode is the operation of the FCMT alone when no power is generated in the WT. It is assumed that the stored hydrogen is exactly $40 \%$ of the tank capacity and thus the full load is supplied. During supplying the load, the stored hydrogen decreased below the $40 \%$ level of the tank capacity at $t$ $\approx 1$ s. At this moment, a certain load dispatch strategy is followed to reduce the supplied power to about $85 \%$ of its initial value. The simulation results for the abovementioned mode are shown in Fig. 6.

The steady-state operation of the FCMT unit shows that $60 \%$ of the load power is generated in the $\mathrm{FC}$ and $40 \%$ is generated in the MT. When the stored hydrogen decreases below the level of $40 \%$ of the tank capacity at $t \approx 1 \mathrm{~s}, 15 \%$ of the load is switched off. Firstly, the load shedding cases a reduction in the angular speed due to the decrease of generated power in the MT (about $0.06 \mathrm{pu}$ ). However, the decrease of the $\mathrm{FC}$ active power (more than $0.09 \mathrm{pu}$ ) results in a corresponding decrease in the input power to the turbine and hence, the angular speed is finally decreased. On the other hand, the controllers succeeded to maintain the rated voltage and frequency at load bus. In addition, the management system regulated the input fuel rate to manage the input thermal power to the turbine to supply the required load power. This reflects the success of the management system and controllers to regulate the overall performance of the unit in this mode.

The second mode is the operation of the WT in parallel with the FCMT unit, where the generated power in the WT is not enough to meet the load demand. As shown in Fig. 7, the increase of the wind speed increases the generated power in the WT.

Fig. 8 illustrates the response of the combined system to turbulent variation in the wind speed. In the first 24 second, the generated power in the WT is not enough to meet the load demand. The FCMT contributes in supplying the load causing a smooth operation attributed to its controllers. At $\approx \approx 24 \mathrm{~s}$, the FCMT unit is switched off since the wind power is increased to exceed the load demand meaning the operation in the third mode. The damping caused by the FCMT unit is observed by comparing the voltage and power oscillations before and after the switching process. The voltage and power experience sudden drops but the controllers succeeded to restore the normal operation.

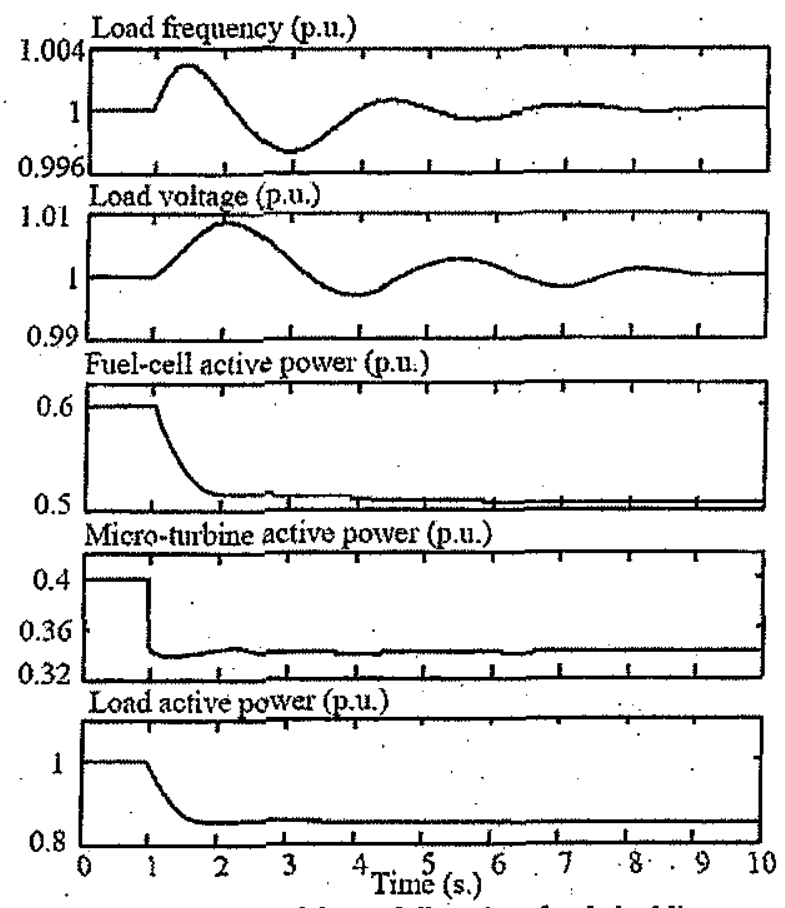

Fig.6, Response of the FCMT unit to load shedding

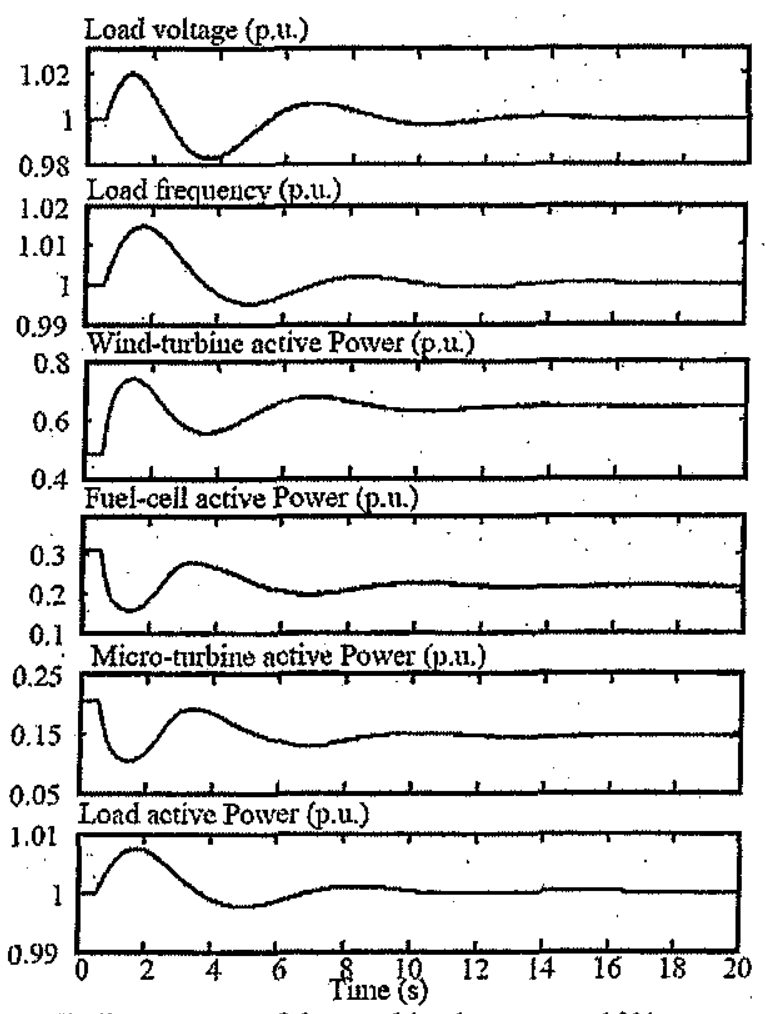

Fig 7, Response of the combined system to $10 \%$ step increase in the wind speed 

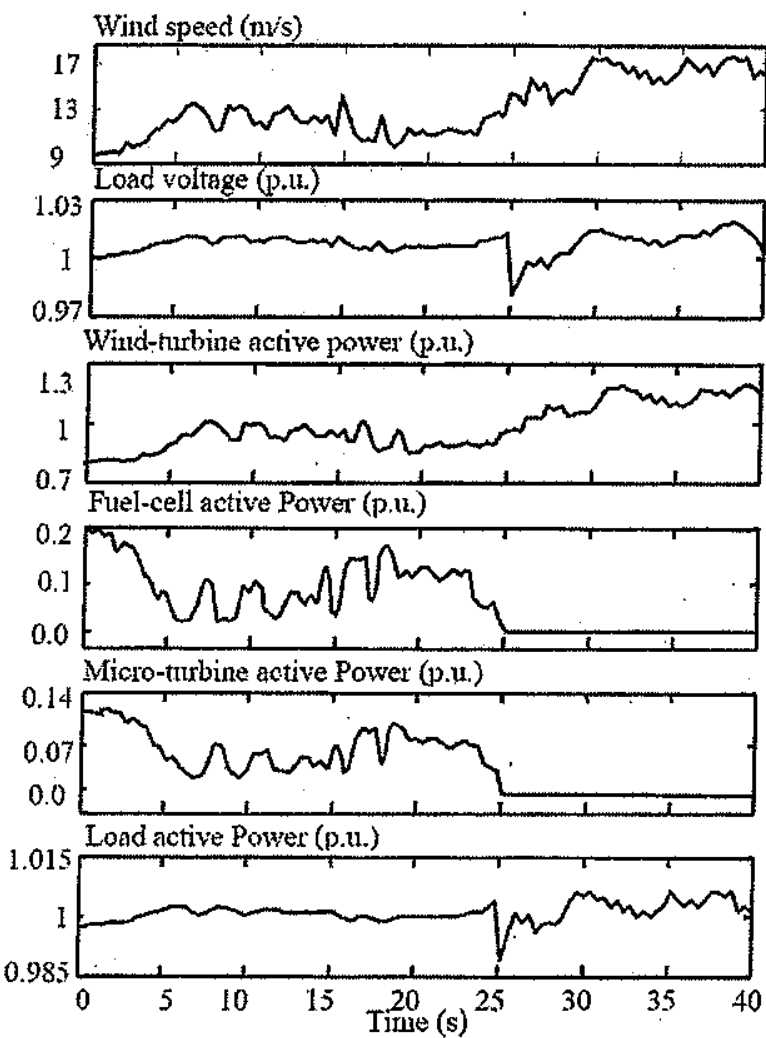

Fig 8, Response of the combined system to continuous variation in the wind speed

Fig. 9 gives the simulation results to another situation related to the third mode, where both the WT and the FCMT unit operate in parallel. The hydrogen tank is assumed to be full and hence, no need for more stored hydrogen. It is better in this case to switch on the FCMT unit to smooth out the oscillations and to utilize the extracted thermal power. This occurs at $t=25 \mathrm{~s}$ and as a result, the system shows more damping. A part of the wind power is used to generate hydrogen through the electrolyser, while the other part supplies the load together with the FCMT power. Although this situation is not efficient, it is better from the quality point of view. In addition, there is no other possibility to utilize the generated power since no batteries or other storage devices are assumed.

\section{CONCLUSION}

The paper discusses the operation of a combined windturbine fuel cell-micro turbine unit to generate a continuous power regardless of the intermittent nature of the wind. The system model with appropriate controllers is presented and the management system is deeply discussed in different operating modes. Due to the effective tracking of the maximum wind power, a sufficient power can be extracted to cover the full load demand either directly or through the FCMT unit. The simulation results show that the controllers respond adequately and efficiently to the system fluctuations. Also, the capability of the combined system to obtain satisfactory dynamic performances is demonstrated with time-domain simulation of four case studies. The system succeeded to maintain acceptable operating conditions with low overshoots under significant changes in wind speed, both step and turbulent, and load shedding. The utilization of the FCMT unit causes more damping in the performance and better regulation of the voltage and frequency. In all cases, the load obtains a steady power at acceptable quality indicating that the hybrid system can deliver electricity reliably and effectively.
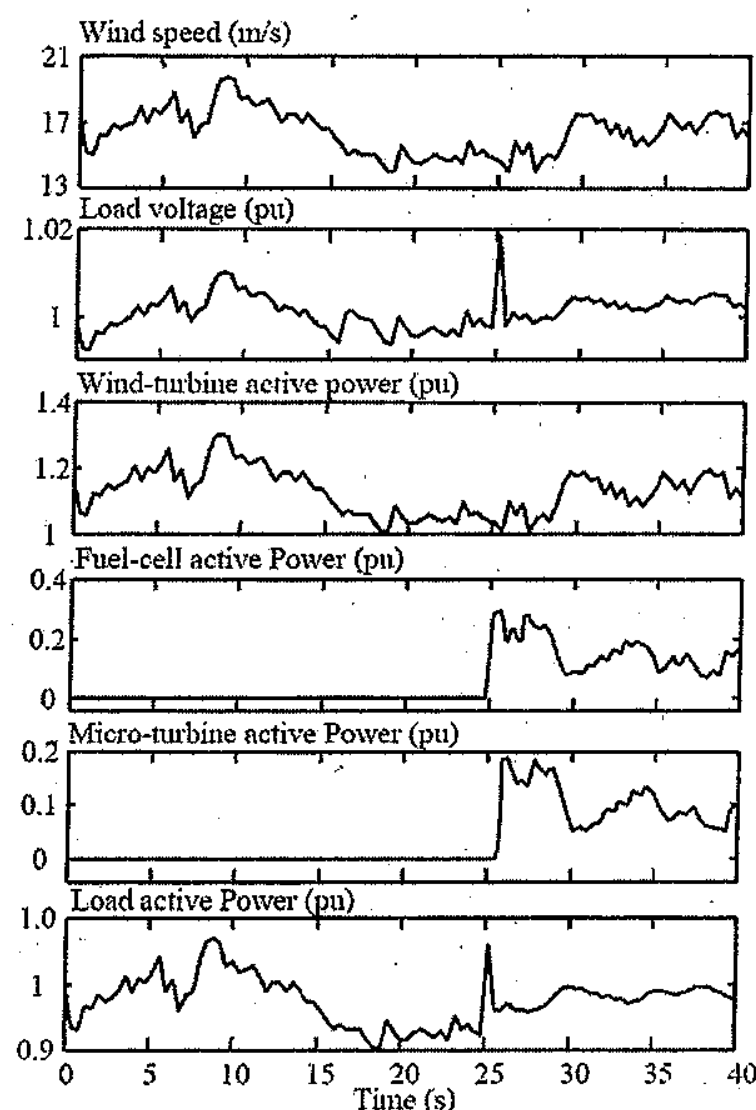

Fig 9, Response of the combined system to continuous variation in the wind speed

\section{APPENDIX}

Parameters of the solid oxide $F C$ equivalent circuit
$P_{\text {rated }}: 75 \mathrm{~kW}$
$\mathrm{T}_{\mathrm{S}}=0.5 \mathrm{~s}$
$\mathrm{T}_{\mathrm{C}}=0.3 \mathrm{~s}$

Parameters of the micro-turbine model
$P_{\text {rated }} ; 40 \mathrm{~kW}$
$\mathrm{H}=5.0 \mathrm{~s}$
$\mathrm{K}_{\mathrm{g}}=25$
$\mathrm{K}_{\mathrm{gen}}=1.0$
$\mathrm{W}_{\min }=0.23 \mathrm{p.u}$
$\tau_{\mathrm{g}}=0.05 \mathrm{~s}$
$\tau_{\text {gen }}=1.5 \mathrm{~s}$
$\tau_{\text {vp }}=0.05 \mathrm{~s}$

Parameters of the Wind-turbine unit

$P_{\text {rated: }}: 100 \mathrm{~kW} \quad R=19.1 \mathrm{~m} \quad \eta_{\mathrm{gb}}=0.96 \%$

\section{REFERENCES}

[1] B. Delfino, F. Fornari, "Modeling and Control of an Integrated Fuel Cell-Wind Turbine System", 
2003 IEEE Bologna PowerTech Conference, June 23-26, Bologna, Italy.

[2] W. Carter and B. M. Diong, "Model of a regenerative fuel cell-supported wind turbine ac power generating system", Próc. IEEE Industry Applications Soc. Annual Meeting, Seattle, WA, Oct 2004, pp. 2778- 2785.

[3] M. Korpas and A. T. Holen, "Operation Planning of Hydrogen Storage Connected to Wind Power Operating in a Power Market", Energy Conversion, IEEE Trans. On, Vol. 21, No. 3, September 2006, pp. 742-749cv.

[4] M. T. Iqbal, "Modeling and control of a wind fuel cell hybrid energy system", Renewable Energy, Vol. 28, No. 2, (2003), pp.223-237.

[5] Shin'ya Obara, "Analysis of a fuel cell micro-grid with a small-scale wind turbine generator", International Journal of Hydrogen Energy, Vol. 32, Issue 3, (2007), pp. 323-336.

[6] M. L. Doumbia, K. Agbossou and M. Dostie, "Power Transfer Analysis in a UtilityInterconnected Fuel Cell Distributed Generator", IEEE Industrial Electronics, IECON $2006-32^{\text {nd }}$ Annual Conference on , Nov. 2006, pp. 43314336, Paris, France.

[7] A. Bilodeau, K. Agbossou, "Control analysis of renewable energy system with hydrogen storage for residential applications" Journal of Power Sources, Vol. 162, (2006), No. 2, pp. 757-764.

[8] D. Das, R. Esmaili, L. Xu and D. Nichols, "An Optimal Design of a Grid Connected Hybrid Wind/Photovoltaic/Fuel Cell System for Distributed Energy Production", Industrial Electronics Society, 2005. IECON 2005. $31^{\text {st }}$ Annual Conference, 6-10 Nov. 2005, pp. 44994504.

[9] J. Morren, S. W. H. de Haan and J. A. Ferreira, "Primary Power/Frequency Control with Wind Turbines and. Fuel Cells" Power Engineering Society General Meeting, 2006, 18-22 June 2006, pp. 1-8.

[10] Ahmed M. Azmy and I. Erlich, "Dynamic simulation of hybrid fuel cell/micro-turbine units integrated into large power systems" The Ninth International Middle-East Power Systems Conference (MEPCON), Egypt, December, 16-18; 2003.

[11] Ahmed M. Azmy and I. Erlich, "Dynamic simulation of fuel cells and micro-turbines integrated with a multi-machine network" Power
Tech Conference Proceedings, 2003 IEEE Bologna, Italy, Vol. 2; June 23-26; 2003, pp. 550555.

[12] E. Muljadi, C. Wang and M. H. Nehrir, "Parallel operation of wind turbine, fuel cell, and diesel generation sources" Power Eng. Society General Meeting, 2004. IEEE, Vol. 2, 6-10 June 2004, pp. $1927-1932$.

[13] I. Erlich, J. Kretschmann, J. Fortmann, S. M. Engelhardt and $\mathrm{H}$. Wrede, "Modeling of Wind Tưrbines Based on Doubly-Fed Induction Generators for Power System Stability. Studies", Power Systems, IEEE Trans. on, Vol. 22, Issue 3, Aug. 2007, pp. $909-919$.

[14] Shinji Kimijima and Nobuhuíde Kasagi, "Performance evaluation of gas turbine-fuel cell hybrid micro generation system" Proceedings of ASME TURBO EXPO 2002, June 3-6, 2002, Amsterdam, the Netherlands.

[15] K. Rajashekara, J. Grieve, D. Daggett "Solid Oxide Fuel Cell/Gas Turbine Hybrid APU System for Aerospace Applications", Industry Applications Conference, 2006. $41^{\text {st }}$ IAS Annual Meeting. Conference Record of the 2006 IEEE, Vol. 5, 8-12 Oct. 2006, pp. 2185-2192, 2006.

[16] M. T. Iqbal, "Simulation of a small wind fuel cell hybrid energy system", Renewable Energy, Vol. 28, (2003), No. 4, pp.511-522.

[17] M. J. Khan, M. T. Iqbal, "Dynamic modelling and simulation of a small wind-fuel cell hybrid energy system", Renewable Energy, Vol. 30, No. 3, (2005), pp. 421-439.

[18] In-Su Bae, Jin-O Kim, Jae-Chul Kim and C. Singh, "Optimal operating strategy for distributed generation considering hourly reliability worth" Power Systems, IEEE Transactions on, Vol. 19, No. 1, February 2004.

[19] Amer Al-Hinai and Ali Feliachi, "Dynamic modelling of a micro turbine used as a distributed generator" System Theory 2002, Proceedings of the $34^{\text {th }}$ Southeastern Symposium on, Huntsville, Alabama, 18-19 March 2002, pp. 209-213.

[20] F. V. Edwards, G. J. W. Dudgeon, J. R. McDonald and W. E. Leithead, "Dynamics of distribution networks with distributed generation" Power Engineering Society Summer Meeting, . Seattle, Washington, USA, 2000 IEEE, Vol. 2, 1620 July 2000, pp. 1032-1037. 